\title{
Communication Profile of de Lange Syndrome
}

\author{
https://doi.org/10.47210/bjohns.2020.v28i3.285
}

Susmi Pani, ${ }^{1}$ Palash Dutta, ${ }^{1}$ Vidushi Saxena, ${ }^{1}$ Asif Ekbal Ansari ${ }^{1}$

\begin{abstract}
Introduction
de Lange Syndrome is an autosomal dominant disorder which was initially described by Vrolik (1849) in a child with severe oligodactayly.

Case Report

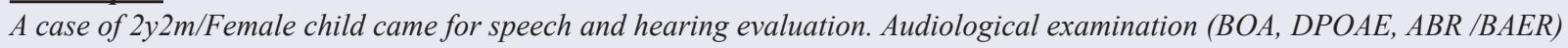
and Speech-Language Evaluation, Psychological Examination were done by expertise clinicians. Previously, the child was diagnosed with de Lange Syndrome. Audiological evaluation diagnosed the child to have moderately severe hearing loss. After speech and language evaluation the child was detected with speech language disorder. After psychological evaluation the child was diagnosed with severe developmental delay and having low IQ range.

Discussion

de Lange syndrome is an autosomal dominant developmental disorder characterized by the sample number of characteristics which requires more rehabilitation options have to be planned. Unfortunately, there is dearth of literature that addresses the characteristics, assessment and intervention of individuals with de Lange syndrome.

$\underline{\text { Keywords }}$

De Lange Syndrome; Communication Disorders
\end{abstract}

ABSTRACT

$\mathrm{I}$ n the 1930s Cornelia de Lange, a Dutch pediatrician reported two unrelated girls with similar features and named the condition "degeneration typus amstelodamnesis". ${ }^{1,2}$ In honor of her formal characterization the term de Lange syndrome is widely used.

de Lange syndrome is a syndrome of congenital anomalies mainly characterized by a prenatal and postnatal growth deficiency; Intellectual disability that usually ranges from moderate to severe; Hearing loss; distinctive facial appearance including arched eyebrows that is often meet in the midline (synophrys), low set ears, small and widely spaced teeth and a small upturned nose; a psychomotor delay; Hirsutism; feeding difficulties; behavioral problems and upper limb defects were also evident. Jackson et.al $(1989)^{3}$ clinically review 310 patients and reported that $33 \%$ of these children were delivered prematurely and intrauterine growth retardation was also evident in many children.

de Lange syndrome is a very rare disorder that is apparent at birth (congenital). Males and females appear to be affected in equal numbers. It has been estimated that de Lange syndrome occurs in approximately one in every 30,000 to one in every 50,000 live births. ${ }^{4}$

\section{Case Report}

A retrospective case study design is adopted for the present study. A 2 year 2 months old male child reported with a complaint of speech\& language problem and reduced hearing sensitivity from both the ears. A detailed case history was taken which reveals that baby was born as premature $b$ and suffered with jaundice at birth and all the developmental milestones were also delayed.

1 - Ali Yavar Jung National Institute for Speech and Hearing Disabilities, Regional Centre, Kolkata

\section{Corresponding author:}

Dr Palash Dutta

email: palashdutta2005@gmail.com 
Table I: Report of Behavioural Observation Audiometry

\begin{tabular}{|c|c|c|}
\hline SOUND STIMULATION & INTENSITY & RESPONSE \\
\hline Clapping & $80 \mathrm{dBHL}$ & Searching \\
\hline Name Calling & $75 \mathrm{dBHL}$ & Startle \\
\hline Bell & $85 \mathrm{dBHL}$ & Eyeblink \\
\hline Drum & $75 \mathrm{dBHL}$ & No Response \\
\hline Daphli & $80 \mathrm{dBHL}$ & Startle \\
\hline $500 \mathrm{~Hz}$ & $75 \mathrm{dBHL}$ & Ceasation of activity \\
\hline $1 \mathrm{KHz}$ & $\mathbf{8 0 d B H L}$ & No response \\
\hline $2 \mathrm{KHz}$ & $85 \mathrm{dBHL}$ & No response \\
\hline $4 \mathrm{KHz}$ & $85 \mathrm{dBHL}$ & \\
\hline
\end{tabular}

A detailed Audiological and Speech and language Evaluation has been done.

\section{Audiological evaluation:}

As the age of the child was 2years 2months, so as per as the protocol for the assessment initially Behavioral Observation Audiometry (BOA)5 was performed. (Table 1)

This report (Table I) indicates that child responds to all verbal stimulus (such as speech cues, name calling) and nonverbal sound stimulus (such as Drum, Bell, Daphli, frequency specific warble tones) between the intensity of $75-85 \mathrm{dBHL}$ and the responses were eye widening, searching, cessation of activity and startle responses. BOA responses were indicative of bilateral moderate to moderately severe hearing Loss.

Further the child was recommended for DP-OAE. DP-OAE screening indicated "REFER" for both the ears indicative of abnormal outer hair cell functioning in the cochlea in both ears.

After doing DP-OAE screening, Auditory Brainstem Response (ABR) test was recommended for the child.

ABR test was done by using an instrument with ANSI S3.1-1999 specifications for the background noise. This test was done by using the protocol.6 (Table II)

This ABR finding (Fig.1) reveals, identifiable peak $\mathrm{V}$ was obtained till $65 \mathrm{dBnHL}$ in right ear which was indicative of moderate hearing loss and identifiable

Table II: ABR Test Protocol

\begin{tabular}{|c|c|}
\hline PARAMETER & SELECTION \\
\hline TRANSDUCER & 'ER-3A inserts \\
\hline TYPE & .Click \\
\hline POLARITY & Rarefaction \\
\hline RAMPING (Window) & Blackman \\
\hline RATE & . Click:21.1/sec \\
\hline
\end{tabular}




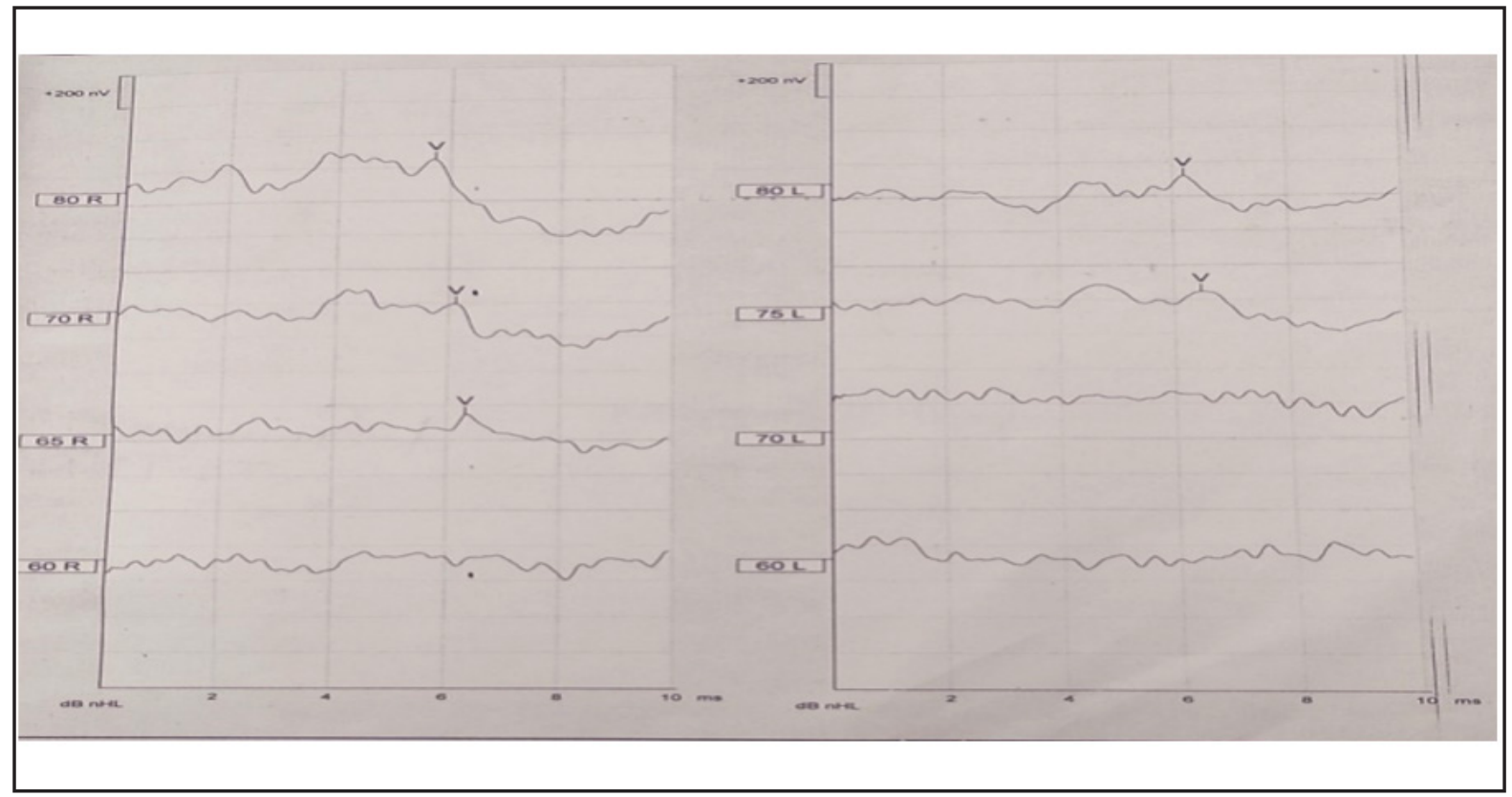

Fig. 1. ABR Report Findings of the Case of de Lange syndrome

peak V was obtained till $75 \mathrm{dBnHL}$ in left ear which was indicative of moderately severe hearing loss.

\section{Speech language evaluation:}

The primary mode of communication was predominantly nonverbal through crying no true word or vocalizations were present.

On OPME examination, all articulators are normal in appearance and functions except the tongue elevations and lateral movements are affected. All the vegetative skills such as blowing, chewing are also affected except sucking.

For assessing receptive expressive language skills REELS was administered on the patient which reveals receptive and expressive language age of the patient is 0-3 months. Level of expression was also which reveals intentional communication behavior for both vocal and motor gestural.

Cognitive prerequisites for language development showed poor skills for all aspects of language development.

COMM DEALL shows delay in all aspects of language development(i.e. Gross motor, Fine motor,
Activity of Daily Living, Receptive, Expressive, Social, Cognitive and Emotional skills all are delayed).

\section{Psychological evaluation:}

Mild Developmental Delay was reported secondary to de Lange syndrome $(\mathrm{DQ}=52)$.

EEG reports revealed normal sleep record.

MRI of brain reports revealed no detectable significant

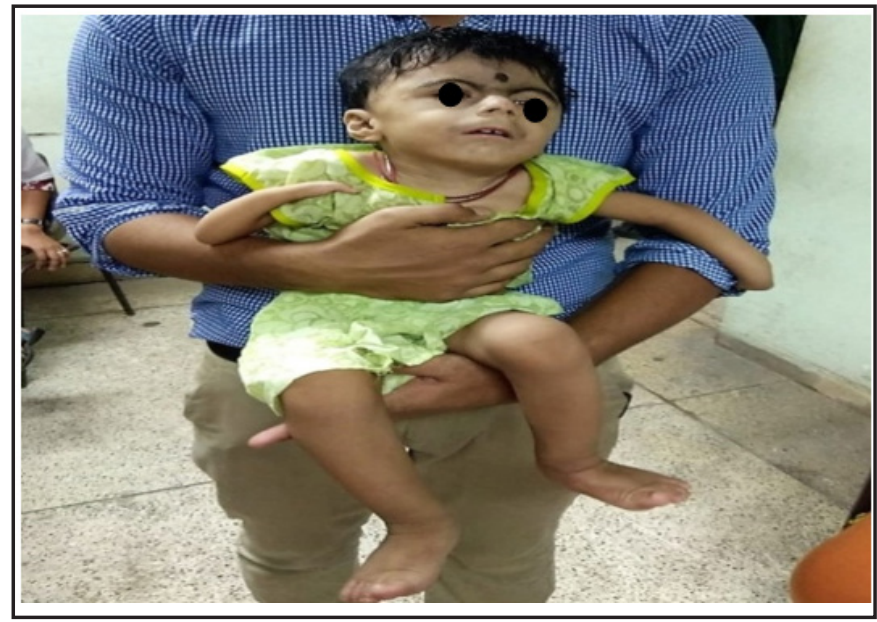

Fig.2. The child with de Lange Syndrome 
Table III: Comparison of ranges between unaided and aided responses

\begin{tabular}{|c|c|c|c|c|}
\hline SOUND & $\begin{array}{l}\text { INTENSITY } \\
\text { (UNAIDED) }\end{array}$ & $\begin{array}{l}\text { RESPONSE } \\
\text { (UNAIDED) }\end{array}$ & INTENSITY (AIDED) & RESPONSE (AIDED) \\
\hline Clapping & 80dBHL & Searching & 50dBHL & Searching \\
\hline Name Calling & 75dBHL & Searching & $50 \mathrm{dBHL}$ & Eye Blink \\
\hline Bell & 85dBHL & Startle & $45 \mathrm{dBHL}$ & Eye widening \\
\hline Drum & 75dBHL & Eyeblink & 45dBHL & Startle \\
\hline Jhankara & 80dBHL & No Response & 50dBHL & Searching \\
\hline $500 \mathrm{~Hz}$ & 75dBHL & Startle & $45 \mathrm{dBHL}$ & Ceasation of activity \\
\hline $1 \mathrm{KHz}$ & 80dBHL & $\begin{array}{c}\text { Ceasation of } \\
\text { activity }\end{array}$ & 50dBHL & Startle \\
\hline $2 \mathrm{KHz}$ & 85dBHL & No response & $50 \mathrm{dBHL}$ & Eye Blink \\
\hline $4 \mathrm{KHz}$ & 85dBHL & No response & $50 \mathrm{dBHL}$ & Head movement \\
\hline
\end{tabular}

abnormality with both the hemispheres were normal in appearance and show abnormal signal intensity, centrum semi ovale and white matter tracts are normal, corpus callosum is normal in size and shape with normal signal pattern, sulci and gyri are normal, cisterns ventricle are normal with septum in the midline, no evidence of hippocampal sclerosis is seen.

Gene karyotyping was done, reports revealed translocation between chromosomes 1 and 4 . Breakage and reunion have occurred at the bands 1q21 and 4q31.3. The segments distal to them have been exchanged i.e. 46, XY, t (1; 4) (q21; q31.3).

Clinical features: clinical examination of the patient reveals following features: Developmental delay; Synophrys: thin eyebrows often meet in the midline; Long eyelashes; Thin downturned lips; Oligodactyly; Low set ears; Hearing loss; Communication delay; Hirsutism: excessive hairs on head and back; small widely spaced teeth, small upturned nose. (Fig.2)

ABR responses of the child revealed moderate hearing loss in the Right ear and moderately severe hearing loss in the left ear. For management, regular use of the hearing aid is recommended to the child which is followed by the Hearing Aid Trial. Patient was recommended for Hearing Aid Trial. (Table III)

BTE hearing aid was tried which was given under the ADIP Scheme or Assistance to Disabled Persons for purchasing/ fitting of aids/ appliances. Where, the patient (Aided) responds to the entire verbal and non- verbal sound stimulus between the intensity of 40-50dBHL. Responses were eye widening, searching, cessation of activity and startle. (Table III)

For management, firstly hearing aids were given to the child with proper programming. Unaided and aided responses were recorded (Table III) to check functional gain of hearing aid and ling six sounds test were to check the child's hearing skills. (Table IV)

\section{Discussion}

The aim of the study is to know the Audiological, Speech Language characteristics and clinical features for the individuals with de Lange syndrome. Due to this rarity speech and language features of de Lange syndrome lack literature. This study may help to investigate the specific clinical features, assessment, and management protocol best suited for patients with de Lange syndrome.

de Lange syndrome is a dominantly inherited developmental disorder characterized by the sample number of characteristics which requires more rehabilitation options have to be planned. Unfortunately, there is dearth of literature that addresses 
Table IV: Comparison of ranges between unaided and aided responses in six ling sound test

\begin{tabular}{|c|c|c|c|c|c|c|c|c|}
\hline \multirow[b]{3}{*}{ SOUNDS } & \multicolumn{4}{|c|}{ WITHOUT LIP READING } & \multicolumn{4}{|c|}{ WITH LIP READING: AIDED } \\
\hline & \multicolumn{2}{|c|}{$\begin{array}{l}\text { UNAIDED } \\
\text { RESPONSE }\end{array}$} & \multicolumn{2}{|c|}{ AIDED RESPONSE } & \multicolumn{2}{|c|}{$\begin{array}{l}\text { UNAIDED } \\
\text { RESPONSE }\end{array}$} & \multicolumn{2}{|c|}{$\begin{array}{c}\text { AIDED } \\
\text { RESPONSE }\end{array}$} \\
\hline & $3 \mathrm{ft}$ & $5 \mathrm{ft}$ & $3 \mathrm{ft}$ & $5 \mathrm{ft}$ & $3 \mathrm{ft}$ & $5 \mathrm{ft}$ & $3 \mathrm{ft}$ & $5 \mathrm{ft}$ \\
\hline$/ \mathbf{a} /$ & $x$ & $x$ & $\sqrt{ }$ & $\sqrt{ }$ & $\sqrt{ }$ & $x$ & $\sqrt{ }$ & $\sqrt{ }$ \\
\hline$/ \mathrm{e} /$ & $x$ & $x$ & $\sqrt{ }$ & $\sqrt{ }$ & $\sqrt{ }$ & $\times$ & $\sqrt{ }$ & $\sqrt{ }$ \\
\hline$/ \mathbf{u} /$ & $x$ & $x$ & $\sqrt{ }$ & $\sqrt{ }$ & $\sqrt{ }$ & $\sqrt{ }$ & $\sqrt{ }$ & $\sqrt{ }$ \\
\hline$/ \mathbf{s} /$ & $x$ & $x$ & $x$ & $x$ & $x$ & $x$ & $x$ & $x$ \\
\hline$/ \mathbf{s h} /$ & $x$ & $x$ & $x$ & $x$ & $x$ & $x$ & $x$ & $x$ \\
\hline$/ \mathbf{m} /$ & $x$ & $x$ & $x$ & $x$ & $x$ & $x$ & $\sqrt{ }$ & $\sqrt{ }$ \\
\hline
\end{tabular}

the characteristics, assessment and intervention of individuals with de Lange syndrome. Therefore more clinical empirical studies are needed to confirm and understand speech \& language characteristics in individuals with de Lange syndrome.

\section{References}

1. Kline A, Moss J, Selicorni A, Bisgaard A, Deardorff M, Gillett $P$ et al. Diagnosis and management of Cornelia de Lange syndrome: first international consensus statement. Nature Reviews Genetics 2018; 19(10):649-66

2. de Knecht-van Eekelen A, Hennekam R. Historical study: Cornelia C. de Lange (1871-1950): A pioneer in clinical genetics.
American Journal of Medical Genetics. 1994;52(3):257-66

3. Jackson L, Kline A, Barr M, Koch S. de Lange syndrome: A clinical review of 310 individuals. American Journal of Medical Genetics 1993; 47(7):940-6

4. Beck B, Fenger K. Mortality, Pathological Findings and Causes of Death in the de Lange Syndrome. Acta Paediatrica 1985; 74(5):765-9

5. Northern J, Downs M, Hayes D. Hearing in children. San Diego: Plural Publishing; 2014

6. Hall JW III. Update on Auditory Evoked Responses: Evidence-Based ABR Protocol for Infant Hearing Assessment. Audiologyonline [Internet] Jan24, 2017[cited 6 April 2020]. Available from: https://www.audiologyonline.com/articles/ update-on-auditory-evoked-responses-19040. 